\title{
Pseudolaric acid B induces caspase-dependent cell death in human ovarian cancer cells
}

\author{
BO YU ${ }^{1}$, DONG-MEI YUE ${ }^{2}$, LIN-HUA SHU ${ }^{2}$, NAI-JING LI $^{3}$ and JIA-HE WANG ${ }^{3}$ \\ Departments of ${ }^{1}$ Neurosurgery, ${ }^{2}$ Pediatrics, and ${ }^{3}$ Geriatrics, \\ Shengjing Hospital of China Medical University, Shenyang, Liaoning 110004, P.R. China
}

Received September 6, 2013; Accepted November 4, 2013

DOI: $10.3892 /$ or.2013.2869

\begin{abstract}
Pseudolaric acid B (PAB) is a diterpene acid isolated from the root and trunk bark of Pseudolarix kaempferi Gordon (Pinaceae). Recent studies have reported that PAB exhibits cytotoxic effects in several cancer cell lines. In the present study, we assessed its antitumor activity and molecular mechanisms in HO-8910 and A2780 ovarian cancer cells in vitro. We found that PAB reduced cell viability and induced apoptosis in a dose- and time-dependent manner in HO-8910 and A2780 human ovarian cancer cells. The induction of apoptosis was also accompanied by the regulation of $\mathrm{Bcl}-2$ and XIAP family proteins, cytochrome $c$ and Apaf-1. Moreover, we observed that PAB treatment resulted in the activation of caspase- 3 and -9 , which may partly explain the anticancer activity of PAB. Collectively, the present study for the first time suggests that PAB enhances apoptosis of HO-8910 and A2780 cells through regulation of $\mathrm{Bcl}-2$ and IAP family proteins. Moreover, the triggering of caspase- 3 and -9 activation mediated apoptotic induction. Our results suggest that PAB may be a new therapeutic option for the treatment of ovarian cancers.
\end{abstract}

\section{Introduction}

Ovarian cancer is a fatal gynecological cancer and a major cause of cancer-related mortality worldwide (1). Regrettably, current chemotherapeutics (platinum/taxane-based drugs) have not markedly prolonged recurrence-free survival of this deadly disease. Thus, there is an urgent need for the development of novel treatment strategies (2).

Rencently, there has been a growing interest in the use of herbs as a source of new drugs for cancer (3). Pseudolaric acid $\mathrm{B}(\mathrm{PAB})$ is a diterpene acid isolated from the root and trunk bark of Pseudolarix kaempferi Gordon (Pinaceae), known as 'Tu-Jin-Pi' (4). PAB contains a structural frame-

Correspondence to: Dr Jia-He Wang, Department of Geriatrics, Shengjing Hospital of China Medical University, Shenyang, Liaoning 110004, P.R. China

E-mail: wangjhcmusj@163.com

Key words: pseudolaric acid B, HO-8910, A2780, apoptosis, XIAP, caspase work that has never been found in any other natural products including a unique poly-hydroazulene with a trans-substitution pattern at the junction sites (5). It has been demonstrated that PAB significantly delayed tumor growth of a taxol-resistant liver cancer without showing obvious toxicity to the animals in vivo, and possessed selective anti-proliferative effects in human cancer cells but not in normal cells in vitro (5).

Apoptosis, a process of programmed cell death (PCD), is crucial during development and to maintain homeostasis. However, dysregulation of this process is implicated in various diseases including cancer $(6,7)$. Cell death inhibition is a very successful strategy that cancer cells employ to combat the immune system and various anticancer therapies (8). Recent evidence has shown that PAB treatment leads to apoptosis in many cancer cells (9-11). However, such an effect of PAB on human ovarian cancer cells has not been reported, and the molecular mechanisms are still not fully understood.

Several genes critical in the regulation of apoptosis have been identified, including XIAP, a member of the IAP family. $\mathrm{X}$-linked inhibitor of apoptosis resistance by effectively inhibiting caspase-3, -7 and -9 (12), IAP gene amplification and increased protein expression occur in many types of cancers, and is an important pathway by which cancer cells acquire resistance to chemotherapy and radiation therapy (13).

In the present study, we analyzed the effect of PAB on cell death and apoptosis in ovarian cancer HO-8910 and A2780 cells. The contribution of caspase-3 and -9, XIAP and Bcl-2 family members, and cytochrome $c$ (cyto $c$ ) and apoptotic protease activating facter-1 (Apaf-1) in PAB-induced cell death was also investigated.

\section{Materials and methods}

Reagents. Monoclonal anti- $\beta$-actin antibodies were purchased from Santa Cruz Biotechnology, Inc. (Santa Cruz, CA, USA). Anti-p53, anti-Bax, anti-Bcl-xL, anti-Bcl-2, anti-Bid, antiXIAP, anti-cIAP1, anti-cIAP2, anti-Smac, anti-survivin, anti-cyto $c$ and anti-Apaf-1 were obtained from New England Biolabs (Beverly, MA, USA). Stocks of the selective XIAP inhibitor Embelin were obtained from Calbiochem Behring (La Jolla, CA, USA). RPMI-1640 and fetal bovine serum (FBS) were purchased from Gibco-BRL (Grand Island, NY, USA). An Annexin V apoptosis detection kit was purchased from R\&D Systems (Abingdon, UK). Cell isolation and 
tissue culture reagents were obtained from Invitrogen-Life Technologies (Lidingö, Sweden). All other reagents were obtained from Sigma-Aldrich (St. Louis, MO, USA).

Cell culture. Ovarian cancer cell lines HO-8910 and A2780 were obtained from China Medical University. The cells were grown in Roswell Park Memorial Institute (RPMI)-1640 medium supplemented with $10 \%$ fetal calf serum (FCS; Gibco), $50 \mu \mathrm{g} / \mathrm{ml}$ penicillin, $50 \mu \mathrm{g} / \mathrm{ml}$ streptomycin and $10 \mu \mathrm{g} / \mathrm{ml}$ neomycin. The cells were incubated at $37^{\circ} \mathrm{C}$ in a humidified $\mathrm{CO}_{2}(5 \%)$ incubator. $\mathrm{HO}-8910$ and $\mathrm{A} 2780$ cells in 24-well flat-bottomed plates were incubated with $\mathrm{PAB}$ at different concentrations $(0,2,4$ and $8 \mu \mathrm{mol} / \mathrm{l})$ for $48 \mathrm{~h}$ or at a concentration of $4 \mu \mathrm{mol} / 1$ for $0,24,48,72$ and $96 \mathrm{~h}$, respectively. In some experiments, Embelin (XIAP inhibitor) was used 30 min prior to $\mathrm{PAB}$ induction.

Cell viability. To assess the overall viability of HO- 8910 and A2780 cells following PAB treatment, the cells were treated as described above. At particular time-points, the HO-8910 or A2780 cells were washed two times with PBS and treated with a $0.4 \%$ solution of trypan blue and visualized as clear cells under a microscope. HO-8910 and A2780 cells that were no longer viable, which had damaged membranes that allowed entry of the dye, were stained blue. Assays were performed in triplicate and repeated at least three times. The number of intact viable cells was expressed as a percentage of total cells and was assessed at different time-points. The percentage of viable cells was calculated as follows: Viable cells $(\%)=$ (total number of viable cells per $\mathrm{ml}$ of aliquot/total number of cells per $\mathrm{ml}$ of aliquot) $\mathrm{x} 100$.

Acridine orange staining. Twenty-five microliters of cell suspension $\left(0.5 \times 10^{6}\right.$ to $2.0 \times 10^{6}$ cells $\left./ \mathrm{ml}\right)$ was incubated with $1 \mu \mathrm{l}$ of Acridine orange (AO) solution, and mixed gently. Each sample was mixed just prior to microscopy and quantification. The cell suspension $(10 \mu \mathrm{l})$ was placed onto a microscopic slide, covered with a glass coverslip and at least 500 cells were examined by fluorescence microscopy using a fluorescein filter.

Hoechst 33258 staining. The cells were stained with Hoechst 33258 (Molecular Probes Inc., Eugene, OR, USA) at a dilution of 1:600 (stock solution, $1 \mathrm{mg} / \mathrm{ml}$ ) for $5 \mathrm{~min}$ in the dark. The samples were observed under a fluorescence microscope. Five hundred cells were counted from each coverslip in turn, and the results were confirmed by visualization of the apoptotic nuclei. There were five coverslips in each group.

Transmission electron microscopy. The cells treated with $0.1 \mu \mathrm{mol} / 1$ paclitaxel were trypsinized and harvested after $24 \mathrm{~h}$. Subsequently the cells were fixed in $4 \%$ glutaral and immersed in Epon 821, embedded in capsules and converged for $72 \mathrm{~h}$ at $60^{\circ} \mathrm{C}$. The cells were then prepared and placed onto an ultrathin section $(60 \mathrm{~nm})$ and stained with uranyl acetate and lead citrate. Cell morphology was examined by transmission electron microscopy.

Flow cytometric analysis. The apoptosis rates of HO-8910 and A2780 cells were quantified by flow cytometry using FITC- conjugated Annexin V and PI. Specific binding of Annexin V was achieved by incubating $10^{6}$ cells in $60 \mu 1$ of binding buffer saturated with Annexin V for 15 min at $4^{\circ} \mathrm{C}$ in the dark. To discriminate between early apoptosis and necrosis, the cells were simultaneously stained with Annexin V and PI prior to analysis. The binding of Annexin V-FITC and PI to the cells was measured by flow cytometry (FACSCalibur; BD Biosciences) using CellQuest software. At least 10,000 cells were counted in each sample. Experiments were performed and interpreted as follows: cells that were Annexin V(-)/PI(-) (lower left quadrant) were considered as living cells, Annexin $\mathrm{V}(+) / \mathrm{PI}(-)$ cells (lower right quadrant) as apoptotic cells, Annexin $\mathrm{V}(+) / \mathrm{PI}(+)$ (upper right quadrant) cells as necrotic or advanced apoptotic cells, and Annexin V(-)/PI(+) (upper left quadrant) cells may be bare nuclei, were considered as cells in late necrosis or cellular debris.

Measurement of cyto c and Apaf-1 release from mitochondria. Cells were treated with $0.1 \%$ DMSO or different concentrations of $\operatorname{PAB}(0,2,4$ and $8 \mu \mathrm{mol} / \mathrm{l})$ for $48 \mathrm{~h}$. Mitochondria and the cytosol were separated using a cyto $c$-releasing apoptosis assay kit. Cells were suspended in cytosol extraction buffer. The cell suspension in extraction buffer was homogenized using a Dounce homogenizer and then centrifuged $(700 \mathrm{x} \mathrm{g}$, $10 \mathrm{~min}$ ) after $10 \mathrm{~min}$ on ice. Then, the collected supernatant was re-centrifuged $\left(10,000 \mathrm{x} \mathrm{g}, 30 \mathrm{~min}, 4^{\circ} \mathrm{C}\right)$. The resulting supernatant (cytosolic fraction) and pellet (mitochondrial fraction) were processed for western blot analysis.

Western blot analysis. Western blot analysis using rabbit polyclonal antibody for p53 (1:2,000 dilution), Bcl-2 (1:2,000 dilution), Bcl-xL (1:2,000 dilution), Bid (1:2,000 dilution), Bax (1:2,000 dilution), XIAP (1:2,000 dilution), cIAP1 (1:2,000 dilution), cIAP2 (1:2,000 dilution), Smac (1:2,000 dilution), Survivin (1:2,000 dilution), cyto $c$ (1:2,000 dilution) and Apaf-1 (1:2,000 dilution) was performed according to standard protocols. $\beta$-actin $(1: 2,000)$ was used to control for equal protein loading. The immunoblots were then washed three times with TBS-T buffer, incubated with a horseradish peroxidaseconjugated secondary antibody (goat anti-rabbit IgM; Santa Cruz Biotechnology), and developed using chemiluminescent substrate (Pierce, Rockford, IL, USA).

Measurement of caspase-3 and-9 activity.HO-8910 and A2780 apoptotic cells were harvested and centrifuged at $1,500 \mathrm{rpm}$ for $10 \mathrm{~min}$. Cells were washed two times with PBS (pH 7.4) and then resuspended with $50 \mu 1$ lysis buffer at $4^{\circ} \mathrm{C}$ and incubated on ice for $10 \mathrm{~min}$. All subsequent steps were performed on ice. After centrifugation, cell extracts were transferred to fresh tubes, and protein concentrations were measured. Each $50 \mu \mathrm{l}$ of cell extract containing $100 \mu \mathrm{g}$ of protein was combined with equal volumes of $2 \mathrm{X}$ reaction buffer in a microplate followed by the addition of $5 \mu \mathrm{l}$ of the peptide substrates of caspase-3 and -9 . After overnight incubation in the dark at $37^{\circ} \mathrm{C}$, samples were read in a microplate reader at $405 \mathrm{~nm}$. Caspase-3 and -9 activity was evaluated by the absorbance ratio of treated/ control samples. In some experiments, inhibitors for caspase-3 (Z-DEVD-FMK) or caspase-9 (Z-LEHD-FMK) were added into fresh medium of HO-8910 or A2780 cells at $1 \mathrm{~h}$ before PAB was added. 

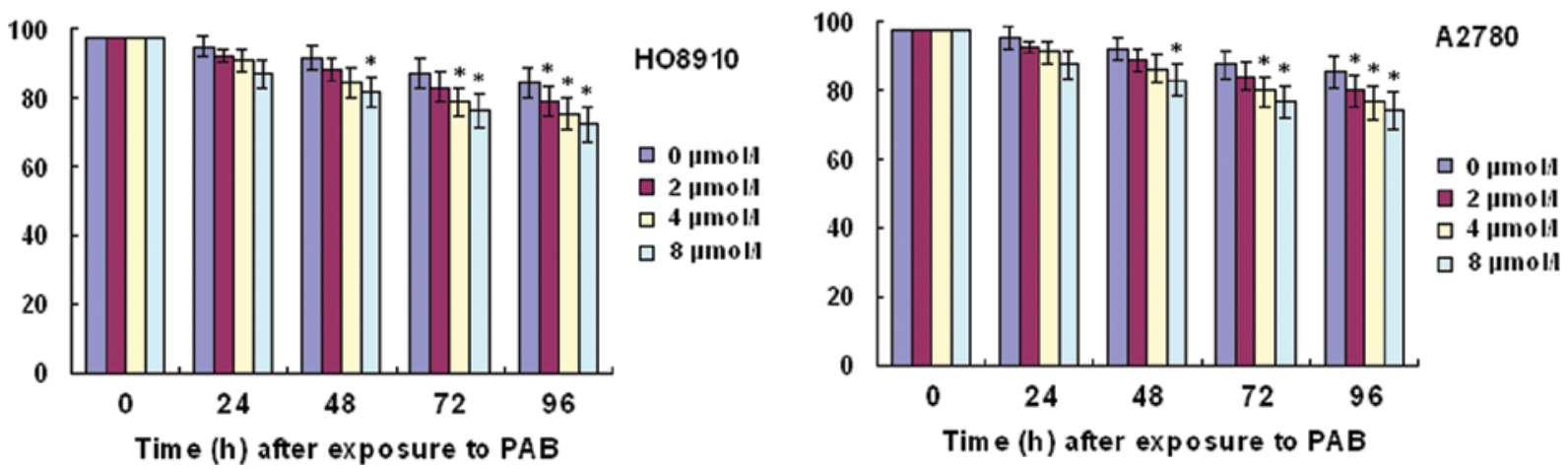

Figure 1. Effect of PAB on HO-8910 and A2780 cells. HO-8910 and A2780 cells were incubated with different concentrations of PAB for 0, $24,48,72$ and 96 h, respectively. Viability of HO-8910 and A2780 cells was determined by trypan blue assay as described in Material and methods.

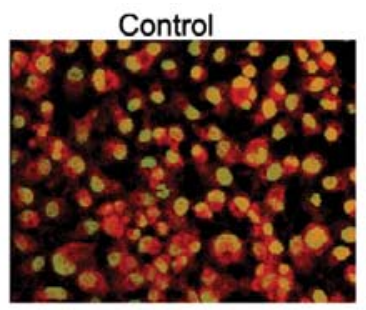

$72 \mathrm{~h}$

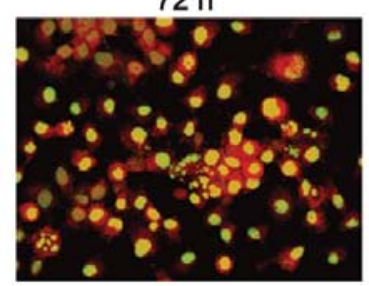

$24 \mathrm{~h}$
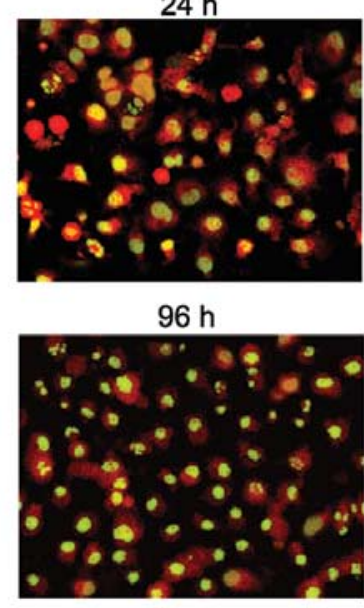

$48 \mathrm{~h}$
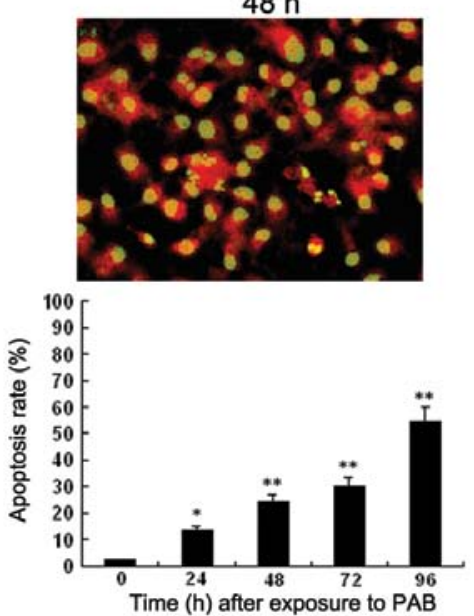

Figure 2. Morphology of HO-8910 cells undergoing apoptosis. HO-8910 were cultured with $4 \mu$ mol/1 PAB for 0, 24 , 48, 72 and 96 h, respectively, and then cells were stained with Acridine orange. Five hundred cells were counted from each coverslip in turn. The percentage of apoptotic cells was calculated by observing 500 cells. ${ }^{*} \mathrm{P}<0.05,{ }^{* * *} \mathrm{P}<0.001$ compared with that of $0 \mathrm{~h}$ alone.

Statistical analysis. Each experiment was carried out in duplicate or triplicate, and three or four independent experiments were performed. Results are expressed as means \pm standard deviation (SD) and analyzed with SPSS 11.5 software. Results were compared using analysis of variance (ANOVA). When ANOVA showed a statistically significant difference, a groupby-group comparison was performed using a t-test with Tukey's correction for multiple comparisons. Statistical significance was set at $\mathrm{P}<0.05$.

\section{Results}

Morphologic analysis of apoptotic HO-8910 cells under light microscopy and transmission electron microscopy. In order to detect HO-8910 or A2780 viability, we performed a trypan blue exclusion assay. Trypan blue staining showed that the percentage of cell viability was decreased with increasing time and concentrations of PAB (Fig. 1).

To investigate whether the growth inhibitory effect was mediated through the induction of apoptosis, we examined the apoptotic morphology of control and PAB-treated HO-8910 cells by Acridine orange staining and transmission electron microscopy. Microscopy of PAB-treated HO-8910 cells revealed morphological changes compared to the control, and the apoptosis rate of HO-8910 increased in a time- and dosedependent manner. Apoptotic cells were characterized by membrane blebbing and nuclear condensation, while necrotic cells were typically larger and lighter with plasma membrane lesions (Fig. 2). The percentage of apoptotic cells was calculated by observing 500 cells. Transmission electron microscope imaging is considered the gold standard in identifying cellular apoptosis due to of its standard and reliable method (14) (Fig. 3).

PAB induces apoptosis in human HO-8910 and A2780 cells. Flow cytometry using FITC-conjugated Annexin V revealed that HO-8910 and A2780 cells exposed to PAB underwent rapid apoptosis (Fig. 4). This effect was positively correlated with the exposure time in the HO-8910 and A2780 cells, and excessive apoptosis was associated with loss of membrane integrity in an increased portion of HO-8910 and A2780 cells, which indicated necrosis or late apoptosis.

$P A B$ treatment modulates the $\mathrm{Bax} / \mathrm{Bcl}-2$ ratio in $\mathrm{HO}-8910$ and $A 2780$ cells. Western blot analysis was carried out to verify the involvement of $\mathrm{Bax}$ and $\mathrm{Bcl}-2$ proteins during 

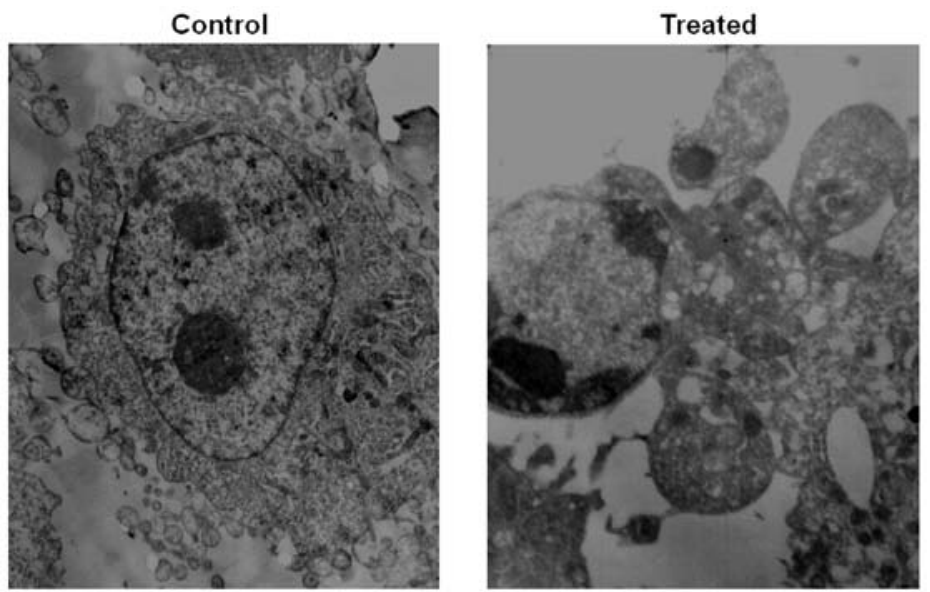

Figure 3. Apoptotic HO-8910 cells visualized using transmission electron microscopy. HO-8910 cells were cultured with $4 \mu$ mol/1 PAB for 0 or $48 \mathrm{~h}$.
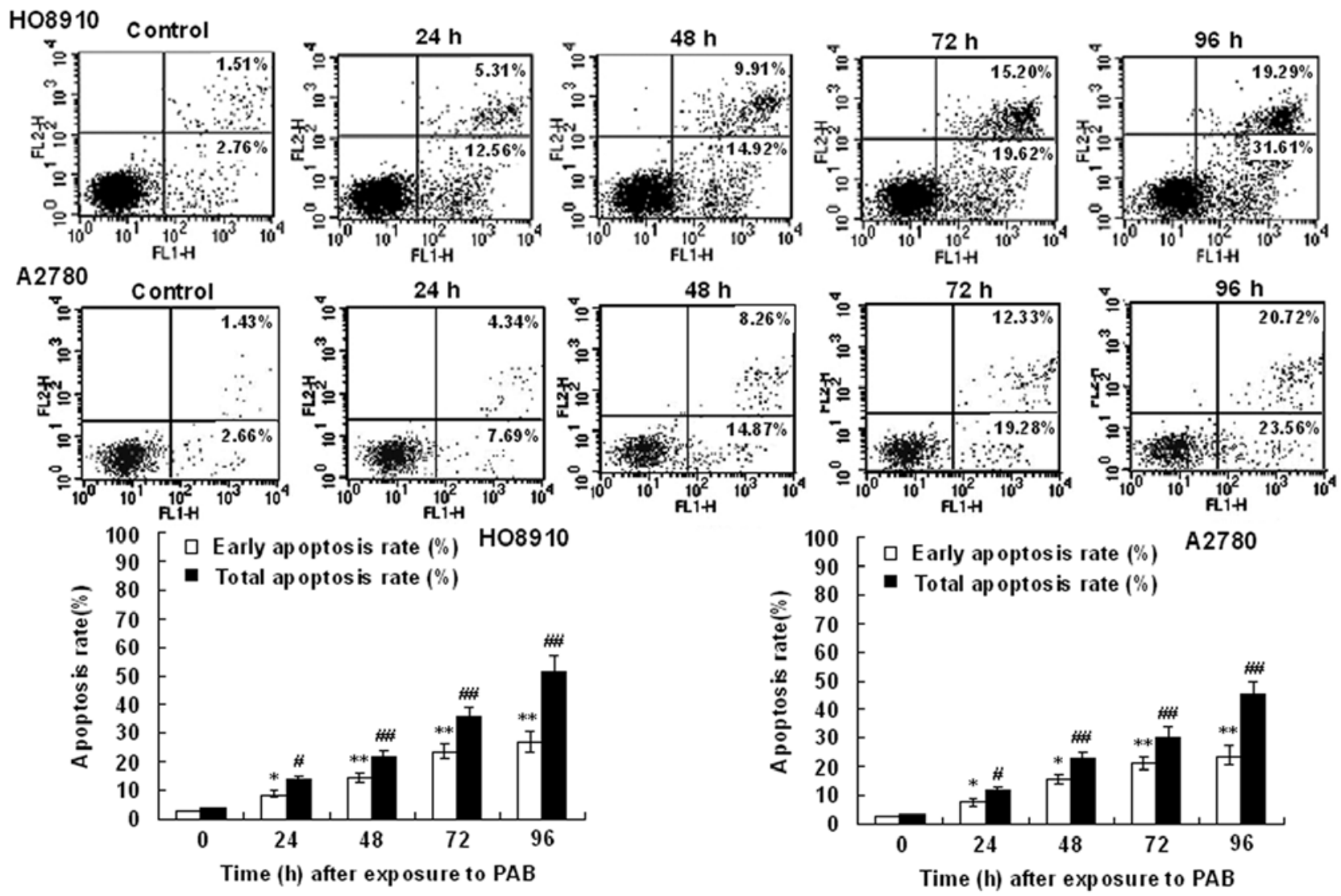

Figure 4. PAB-induced apoptosis in HO-8910 and A2780 cells. HO-8910 and A2780 cells were challenged with $4 \mu \mathrm{mol} / 1 \mathrm{PAB}$ for 0, 24, 48,72 and $96 \mathrm{~h}$, respectively. After treatment, cells were incubated with FITC-conjugated Annexin V (AV) and propidium iodide (PI) double staining. Flow cytometric analysis was performed, and the data shown are representative of three separate experiments. The lower right quadrants represent early apoptotic cells that were stained with Annexin $\mathrm{V}$ but not by propidium iodide. The upper right quadrants represent late apoptotic cells that were stained by both Annexin $\mathrm{V}$ and propidium iodide. ${ }^{* \#} \mathrm{P}<0.05,{ }^{* * * \# \#} \mathrm{P}<0.001$ compared with that of $0 \mathrm{~h}$ alone.

PAB-induced apoptosis of HO-8910 and A2780 cells. The expression of Bcl-2 and Bcl-xL proteins was downregulated and the expression of $\mathrm{p} 53$ and Bax proteins was upregulated in the PAB-treated cells (Fig. 5). However, the expression of Bid was not altered in the two types of cells. These results suggest that PAB induced apoptosis via alteration of the Bax/ Bcl-2 ratio in HO-8910 and A2780 cells.
PAB induces HO-8910 and A2780 apoptotic cell death via modulation of XIAP family proteins. In order to ascertain the apoptotic mechanism in HO-8910 cells induced by PAB, we examined anti-apoptotic protein expression. Members of the mammalian IAP family mainly include XIAP, cIAP-1 and cIAP-2. The results showed that the transcription and expressions of cIAP1/2, XIAP and survivin were decreased in a 

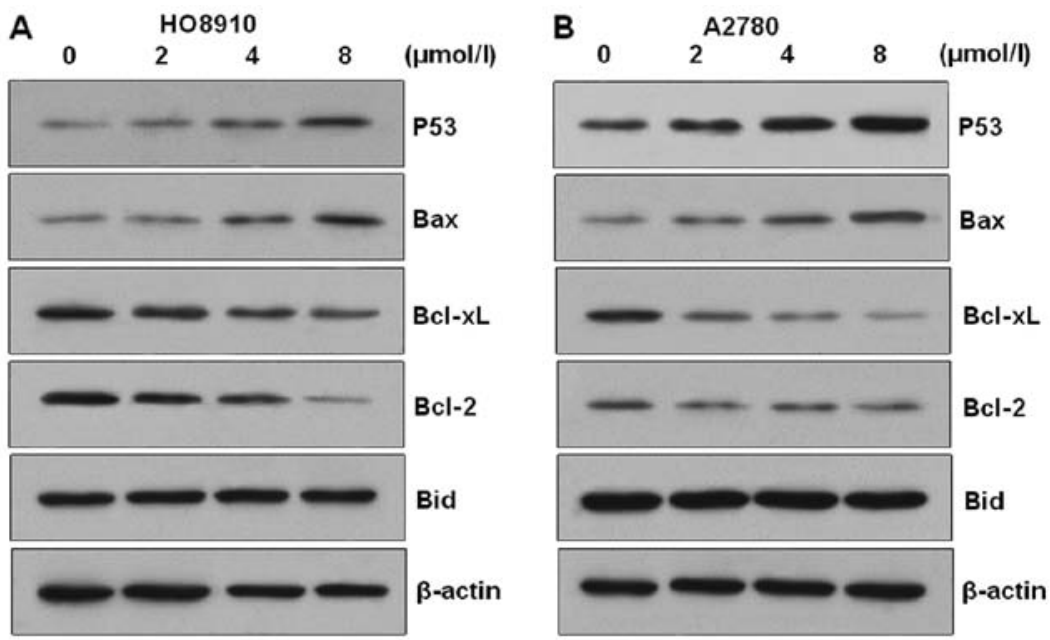

Figure 5. p53 and Bcl-2 family proteins are involved in HO-8910 and A2780 cell apoptosis induced by PAB. The expression of p53 and Bcl-2 family proteins in (A) HO-8910 and (B) A2780 cells challenged with 0,2, 4 and $8 \mu \mathrm{mol} / 1 \mathrm{PAB}$, respectively, for $48 \mathrm{~h}$. $\beta$-actin was used as a loading control. The data are from one representative experiment.

A

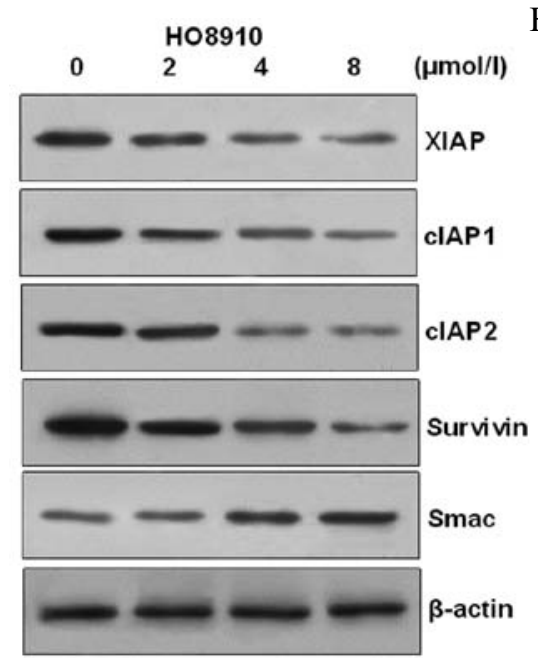

B

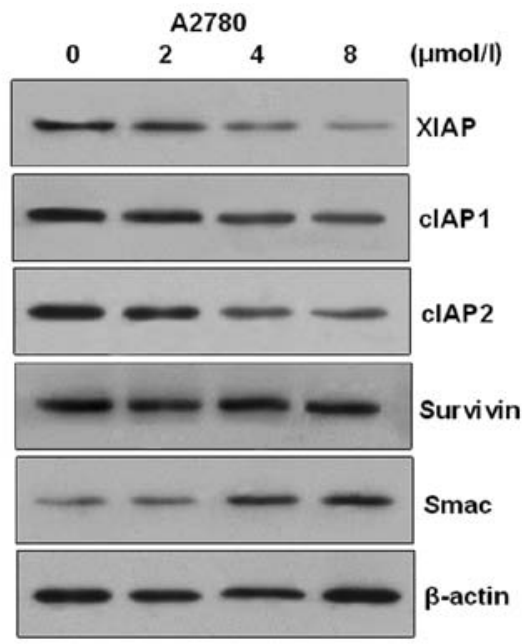

Figure 6. XIAP family proteins are involved in HO-8910 and A2780 cell apoptosis induced by PAB. The expression of XIAP, cIAP1, cIAP2, survivin and Smac in (A) HO-8910 and (B) A2780 cells challenged with 0,2, 4 and $8 \mu \mathrm{mol} / 1 \mathrm{PAB}$, respectively, for $48 \mathrm{~h}$. $\beta$-actin was used as a loading control. The data are from one representative experiment.

dose-dependent manner after challenge with PAB in HO-8910 and A2780 cells. However, the transcription and expression of Smac (second mitochondria-derived activator of caspase), which is an intrinsic antagonist of XIAP, were increased in a time-dependent manner (Fig. 6). These results suggest that changes in expression of cIAP1/2, survivin, Smac and XIAP may contribute to PAB-induced apoptogenesis in HO-8910 and A2780 cells.

$P A B$ induces cyto $c$ and Apaf-1 release from the mitochondria. Mitochondria play an essential role in the apoptosis triggered by chemical (anticancer) agents. The mitochondrial response includes the release of cyto $c$ and Apaf- 1 into the cytosol. Therefore, we tested the effect of PAB on cyto $c$ and Apaf-1 release. To analyze the involvement of mitochondria in HO-8910 and A2780 cells, proteins from the cytosolic frac- tion were prepared and analyzed using western blot analysis. Treatment of HO-8910 and A2780 cells with 0, 2, 4 and $8 \mu \mathrm{mol} / \mathrm{l} \mathrm{PAB}$, respectively, for $48 \mathrm{~h}$ resulted in an increase in cyto $c$ and Apaf-1 levels in a dose-dependent manner. These results indicate that PAB promotes cyto $c$ and Apaf-1 release from mitochondria into the cytosol (Fig. 7).

Effects of an inhibitor of XIAP on PAB-induced HO-8910 and $A 2780$ cell apoptosis. To identify the relevance of the XIAP signaling pathway in controlling the apoptotic cell death by PAB, inhibition assays were performed with Embelin (a specific inhibitor of XIAP). The percentage of apoptosis was determined by flow cytometery. HO-8910 and A2780 cells were pretreated with $20 \mu \mathrm{M}$ Embelin for $30 \mathrm{~min}$, and then cultured with $4 \mu \mathrm{mol} / 1 \mathrm{PAB}$ for $48 \mathrm{~h}$. The cells were stained with Hoechst 33258 and the samples 

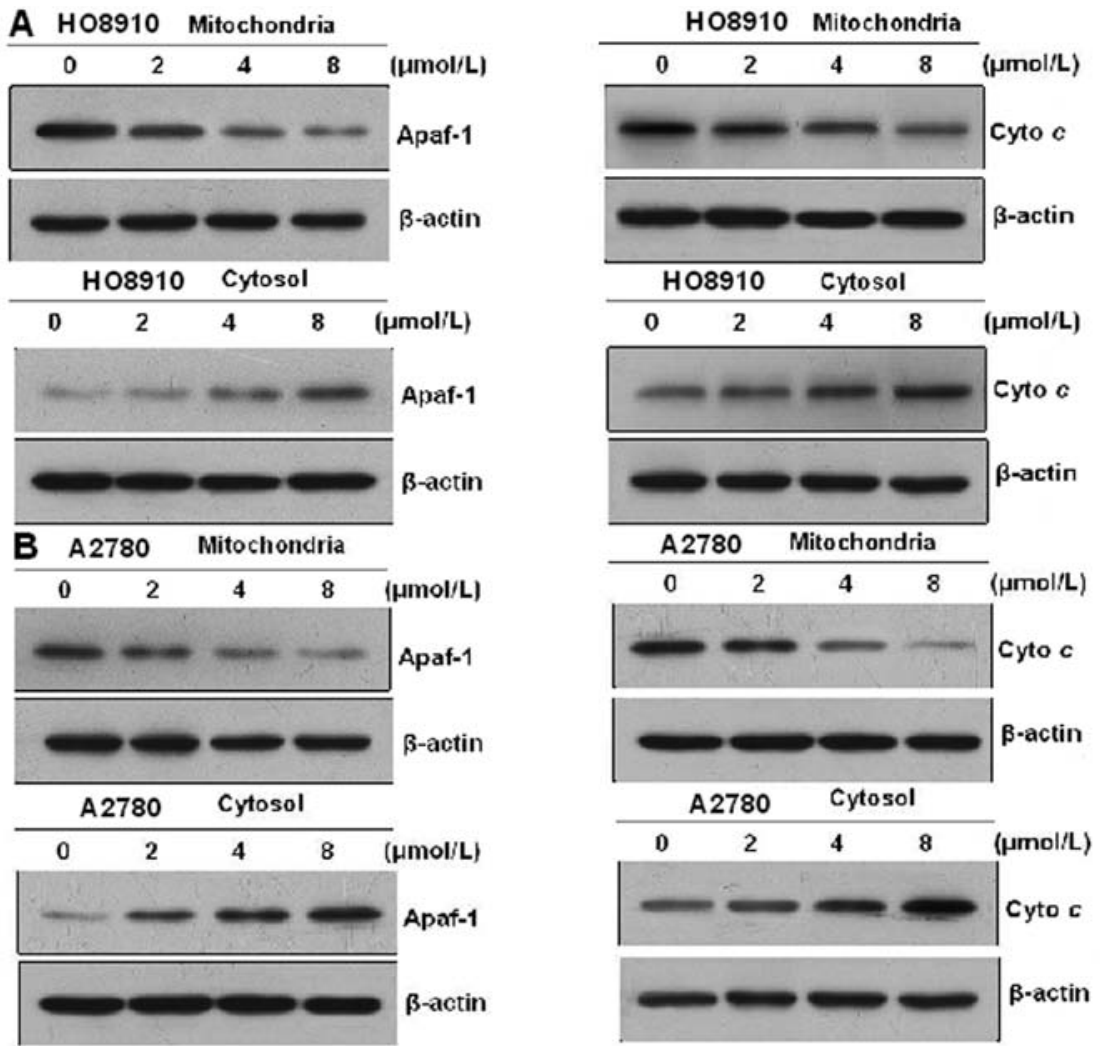

Figure 7. Cytochrome $c$ and Apaf-1 proteins are involved in HO- 8910 and A2780 cell apoptosis induced by PAB. The expression of cytochrome $c$ and Apaf-1 proteins in (A) HO-8910 and (B) A2780 cells challenged with 0,2, 4 and $8 \mu \mathrm{mol} / 1 \mathrm{PAB}$, respectively, for $48 \mathrm{~h}$. The data are from one representative experiment.

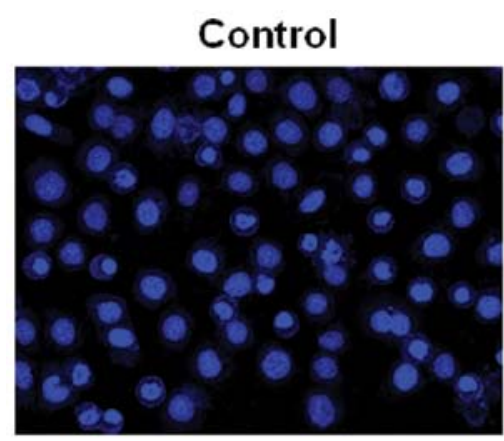

PAB

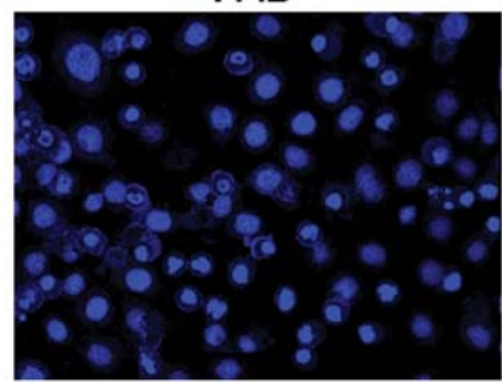

\section{Embelin}

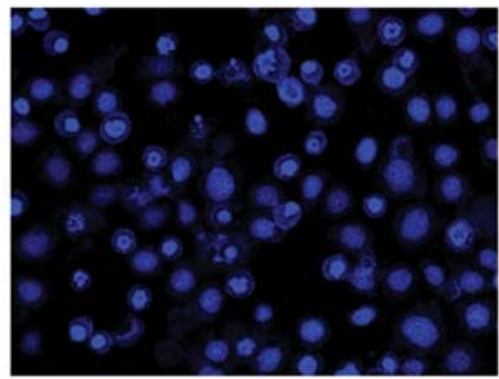

PAB+Embelin

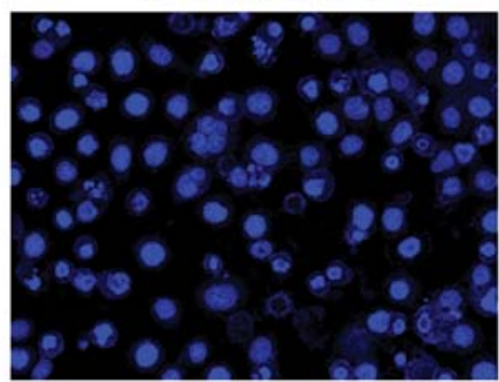

Figure 8. Morphology of HO-8910 cells following treatment with $20 \mu \mathrm{M}$ Embelin, $4 \mu \mathrm{mol} / 1 \mathrm{PAB}$ or $20 \mu \mathrm{M}$ Embelin plus $4 \mu \mathrm{mol} / 1 \mathrm{PAB}$ for $48 \mathrm{~h}$. HO-8910 control and treated cells were stained with Hoechst 33258 dye.

were observed under a fluorescence microscope. The results showed that Embelin significantly increased the apoptosis rate (Fig. 8). The same results were also showed by flow cytometric analysis (Fig. 9).
Expression of caspase-3 and -9 activity. The expression of caspase- 3 and -9 activity in HO-8910 and A2780 cells incubated in the presense of PAB is presented in Fig. 10. Treatment of HO-8910 and A2780 cells with PAB for $48 \mathrm{~h}$ at concentrations 

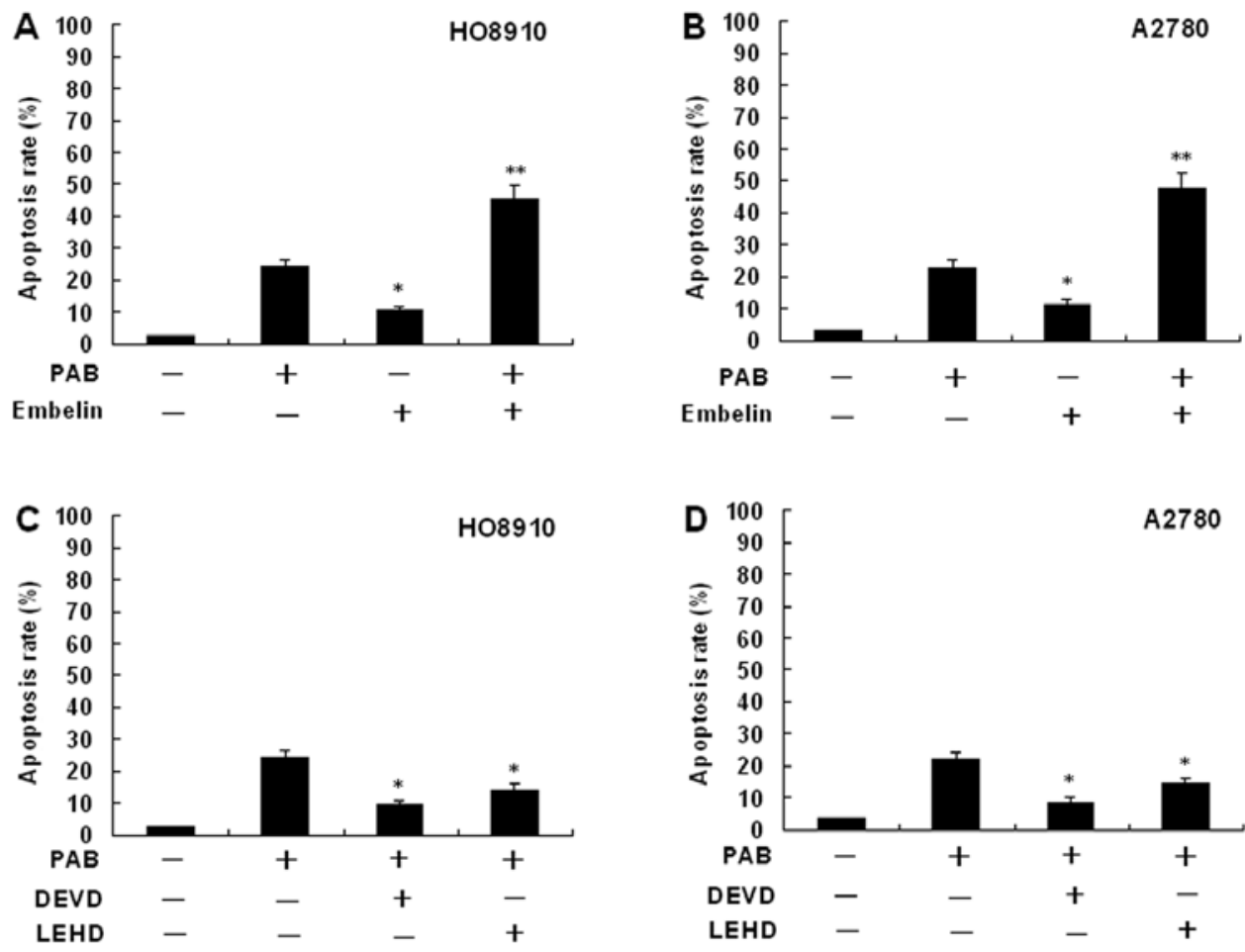

Figure 9. Effect of inhibitors of XIAP (Embelin), caspase-3 (DEVD), or caspase-9 (LEHD) on PAB-induced HO-8910 and A2780 cell apoptosis. (A and B) HO-8910 and A2780 cells were treated with $4 \mu \mathrm{mol} / 1 \mathrm{PAB}$ and incubated for $48 \mathrm{~h}$ with or without $20 \mu \mathrm{M}$ Embelin for 30 min. (C and D) HO-8910 and A2780 cells were treated with $4 \mu \mathrm{mol} / 1$ PAB and incubated with DEVD or LEHD for $30 \mathrm{~min}$. After treatment, cells were incubated with FITC-conjugated Annexin V $(\mathrm{AV})$ and PI double staining. Flow cytometric analysis was performed. Values represent means \pm SD of five experiments performed in duplicate. (A and B) ${ }^{*} \mathrm{P}<0.05,{ }^{* *} \mathrm{P}<0.001$ compared with that of the control. (C and D) ${ }^{*} \mathrm{P}<0.05$ compared with that of $\mathrm{PAB}$ alone.
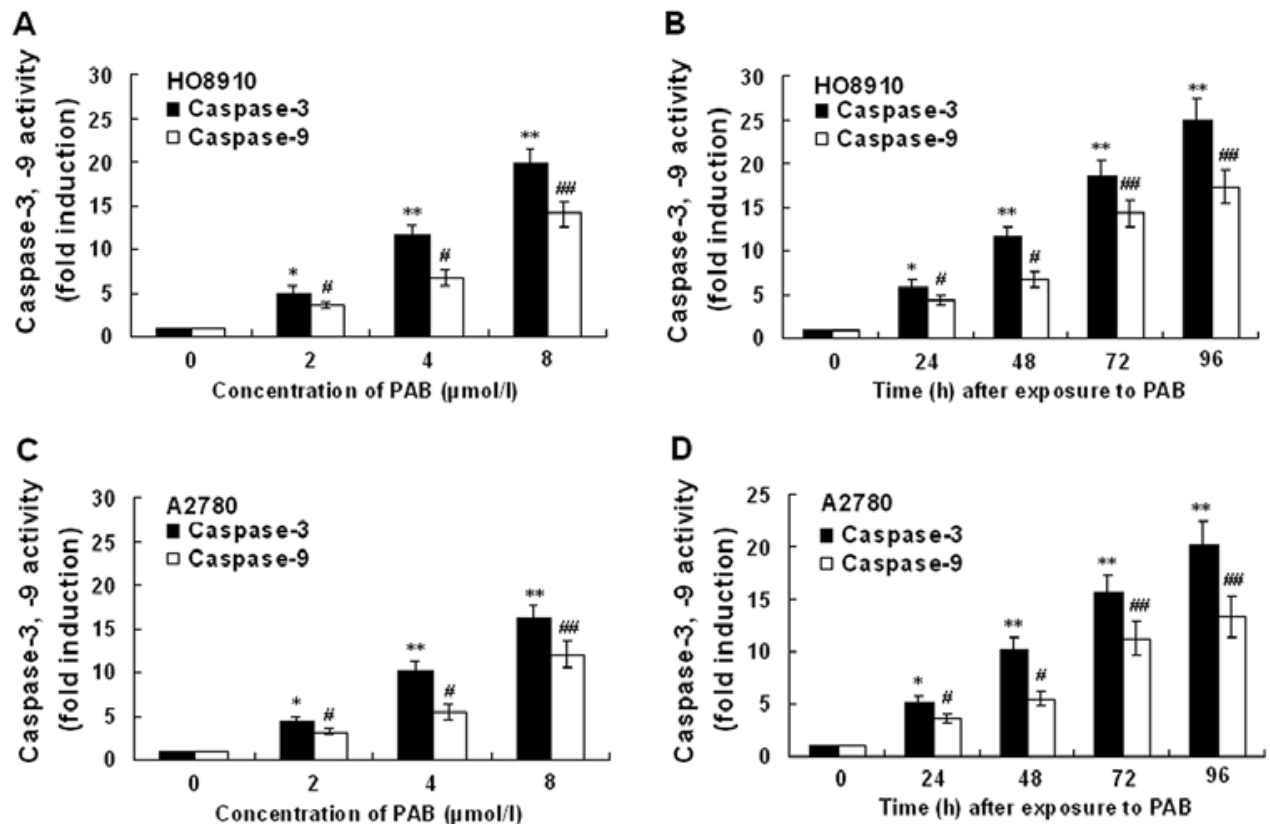

Figure 10. Effect of PAB on the activity of caspase-3 and -9 in HO-8910 and A2780 cells. The cells were treated with $0,2,4$ and $8 \mu \mathrm{mol} / 1 \mathrm{PAB}$, respectively, for $48 \mathrm{~h}$ or with $4 \mu \mathrm{mol} / 1 \mathrm{PAB}$ for 0, 24, 48, 72 and $96 \mathrm{~h}$, respectively. (A) Dose-dependent effect of PAB-induced caspase-3 and -9 activity in HO-8910 cells (B) Time-dependent effect of PAB-induced caspase-3 and -9 activity in HO-8910 cells. (C) Dose-dependent effect of PAB-induced caspase-3 and -9 activity in A2780 cells. (D) Time-dependent effect of PAB-induced caspase-3 and -9 activity in A2780 cells. Values represent means \pm SD of five experiments performed in duplicate. ${ }^{*, *} \mathrm{P}<0.05,{ }^{* *, \# t} \mathrm{P}<0.001$ compared with that of control.

of $0,2,4$ and $8 \mu \mathrm{mol} / 1$, respectively, or for different times at a concentration of $4 \mu \mathrm{mol} / 1$ showed marked increase in caspase-3 and -9 activation. Activity of caspase-3 and -9 in HO-8910 and A2780 cells following PAB treatment showed dose- and time- 
dependent upregulation. Inhibition of XIAP with Embelin potentiated the PAB-induced caspase- 3 and -9 activity (data not shown). In order to assess whether PAB-induced cell death occurred due to caspase activation, we used the caspase inhibitor Z-DEVD-FMK (specific for caspase-3) or Z-LEHD-FMK (specific for caspase-9) (Fig. 9). PAB induced cell death in HO-8910 and A2780 cells. The pretreatment of HO-8910 and A2780 cells with Z-DEVD-FMK or Z-LEHD-FMK inhibited PAB-induced apoptosis, suggesting the involvement of caspase(s) in PAB-induced cell death.

\section{Discussion}

Several trials are currently being performed to investigate the effect of pseudolaric acid B on various types of solid tumors, including ovarian cancer $(4,15)$. However, knowledge concerning the mechanism by which this compound induces cell death is still limited. Thus, our research was designed to determine whether PAB induces apoptosis in ovarian cancer cells. To the best of our knowledge, the present study for the first time demonstrated that PAB induced HO-8910 and A2780 cell apoptosis in a time- and dose-dependent manner.

A characteristic feature of human cancers is the inability to mount a proper apoptotic response during tumor progression or upon treatment with cytotoxic therapies (16). Therefore, evasion of apoptosis constitutes a critical cause of primary or acquired treatment resistance that frequently occurs in various types of human cancers (17). The molecular pathways leading to apoptosis are evolutionarily conserved and controlled (18). Apoptotic signaling pathways are the most promising therapeutic targets for cancer treatment $(19,20)$.

The Bcl-2 family proteins play an essential role in the apoptotic process. They are regulators of mitochondrial membrance permeability and intermembrane space protein efflux according to the opposing fractions of anti-apoptosis members and pro-apoptosis members (21). The ratio of anti- and pro-apoptotic protein expression, such as Bcl-2/ Bax, is crucial for the induction of apoptosis, and it decides the susceptibility of cells to undergo apoptosis (22). Bcl-2 and Bcl-xL act as anti-apoptotic factors, and Bax acts as a proapoptotic factor. In the present study, treatment of HO-8910 and A2780 cells with PAB markedly downregulated Bcl-2 and Bcl-xL expression, upregulated Bax and P53, whereas the expression of Bid did not change.

The mitochondrion is generally believed to be the key regulatory element of cell death and the target of many proapoptotic signaling pathways (23). Smac/DIABLO (second mitochondria-derived activator of caspases or direct IAP binding protein with low $\mathrm{pI}$ ), a mitochondrial protein that is released together with cyto $c$ from the mitochondria in response to apoptotic stimuli, was found to promote caspase activation by binding and neutralizing the IAPs via its N-terminal $(24,25)$ Smac release from mitochondria (26) is a general feature of apoptosis. In the present study, we showed that PAB upregulated the expression of Smac in HO-8910 and A2780 cells. Our results also indicate that PAB promotes cyto $c$ and Apaf-1 release from mitochondria into the cytosol.

Bax/Bak mediate mitochondrial outer membrane permeabilization (MOMP), with consequent release of apoptogenic factors from mitochondria into the cytosol (cyto $c$, Smac/DIABLO). These apoptogenic factors precipitate activation of the caspase cascade and cell-killing via Apaf-1-mediated activation of the initiator caspase, caspase-9, as well as by derepression of effector caspases by blocking their antagonist XIAP $(27,28)$. Inhibitor of apoptosis (IAP) proteins are a family of endogenous anti-apoptotic proteins (29). Elevated expression of IAP proteins combined with their well-established functional importance for survival of tumor tissues and resistance to anticancer therapies makes IAP proteins attractive targets for therapeutic intervention (8). Among the IAPs, cellular IAP1 (cIAP1) and cIAP2 play a key role in the regulation of death receptor-mediated apoptosis, whereas X-linked IAP (XIAP) inhibits both death receptormediated and mitochondrial-mediated apoptosis by binding to and inhibiting caspase-3/7 and caspase-9; three cysteine proteases critical for execution of apoptosis (30). In the present study, we showed that PAB downregulated the expression of XIAP, survivin, cIAP-2 and Bcl-2 and upregulated the expression of Bax. It was also shown that PAB promoted cyto $c$ and Apaf-1 release from mitochondria into the cytosol.

Embelin (2,5-dihydroxy-3-undercyl-1,4-benzoquinone; $\mathrm{C}_{17} \mathrm{H}_{26} \mathrm{O}_{2}$; molecular weight, 294.39) is a type of extract from Japanese Ardisia Herb, and its traditional use in Chinese herbal medicine is to dispel intestinal parasites. It was later identified as a novel cell permeable inhibitor of XIAP (31). To more directly link the XIAP signaling pathway with caspase activation, we examined PAB-mediated caspase-3 and -9. In our study, inhibition of XIAP significantly increased caspase-3 and -9 activitiy. Moreover, Embelin significantly increased the apoptosis rate.

In conclusion, we found that PAB inhibited cell growth and induced the apoptosis of HO-8910 and A2780 cells. We also studied the underlying mechanisms involved in PAB-induced apoptosis. In the present study, there was a tendency of alterations showing a decreased expression level of Bcl-2, cIAP1/2, survivin and XIAP, and also with an increased expression level of Smac and activation of caspase-3 and -9. Moreover, PAB induced cyto $c$ and Apaf-1 release from the mitochondria.

\section{Acknowledgements}

The present study was supported by the Provincial Natural Science Foundation of Liaoning Province (201202270), the Outstanding Scientific Fund of Shengjing Hospital (201206), Tackle Key Problems in Science and Technology of Liaoning Province (2011225020), and Tackle Key Problems in Science and Technology of Shenyang City (F12-193-9-20).

\section{References}

1. Yin F, Liu X, Li D, Wang Q, Zhang W and Li L: Tumor suppressor genes associated with drug resistance in ovarian cancer. Oncol Rep 30: 3-10, 2013.

2. Kodigepalli KM, Dutta PS, Bauckman KA and Nanjundan M: SnoN/SkiL expression is modulated via arsenic trioxide-induced activation of the PI3K/AKT pathway in ovarian cancer cells. FEBS Lett 587: 5-16, 2013.

3. Ishii T, Kira N, Yoshida T and Narahara H: Cucurbitacin D induces growth inhibition, cell cycle arrest, and apoptosis in human endometrial and ovarian cancer cells. Tumour Biol 34: 285-291, 2013. 
4. Yu JH, Liu CY, Zheng GB, et al: Pseudolaric acid B induced cell cycle arrest, autophagy and senescence in murine fibrosarcoma 1929 cell. Int J Med Sci 10: 707-718, 2013.

5. Ma G, Chong L, Li XC, Khan IA, Walker LA and Khan SI: Selective inhibition of human leukemia cell growth and induction of cell cycle arrest and apoptosis by pseudolaric acid B. J Cancer Res Clin Oncol 136: 1333-1340, 2010.

6. Thompson CB:Apoptosis in the pathogenesis and treatment of disease. Science 267: 1456-1462, 1995.

7. Fulda S: Apoptosis pathways and their therapeutic exploitation in pancreatic cancer. J Cell Mol Med 7: 1221-1227, 2009.

8. Varfolomeev E and Vucic D: Inhibitor of apoptosis proteins: fascinating biology leads to attractive tumor therapeutic targets. Future Oncol 7: 633-648, 2011

9. Tong J, Yin S, Dong Y, Guo X, Fan L, Ye M and $\mathrm{Hu} \mathrm{H}$ : Pseudolaric acid B induces caspase-dependent apoptosis and autophagic cell death in prostate cancer cells. Phytother Res 27 885-891, 2013.

10. Qi M, Yao G, Fan S, Cheng W, Tashiro S, Onodera S and Ikejima T: Pseudolaric acid B induces mitotic catastrophe followed by apoptotic cell death in murine fibrosarcoma L929 cells. Eur J Pharmacol 683: 16-26, 2012.

11. Khan M, Zheng B, Yi F, et al: Pseudolaric acid B induces caspase-dependent and caspase-independent apoptosis in $\mathrm{u} 87$ glioblastoma cells. Evid Based Complement Alternat Med 2012: 957568, 2012.

12. Carter BZ, Mak DH, Wang Z, Ma W, Mak PY, Andreeff M and Davis RE: XIAP downregulation promotes caspase-dependent inhibition of proteasome activity in AML. Leuk Res 37: 974-979, 2013.

13. Cao Z, Zhang R, Li J, et al: X-linked inhibitor of apoptosis protein (XIAP) regulation of cyclin D1 protein expression and cancer cell anchorage-independent growth via its E3 ligasemediated protein phosphatase $2 \mathrm{~A} / \mathrm{c}-\mathrm{Jun}$ axis. J Biol Chem 288 20238-20247, 2013.

14. Yao SQ, Rojanasakul LW, Chen ZY, et al: Fas/FasL pathwaymediated alveolar macrophage apoptosis involved in human silicosis. Apoptosis 16: 1195-1204, 2011.

15. Supiot S, Gouraud W, Campion L, et al: Early dynamic transcriptomic changes during preoperative radiotherapy in patients with rectal cancer: a feasibility study. World J Gastroenterol 19: 3249-3254, 2013.

16. Fulda S: Tumor resistance to apoptosis. Int J Cancer 124: 511-515, 2009.

17. Fulda S: Inhibitor of apoptosis (IAP) proteins as therapeutic targets for radiosensitization of human cancers. Cancer Treat Rev 38: 760-766, 2012.
18. Paramasivam A, Sambantham S, Shabnam J, et al: Anti-cancer effects of thymoquinone in mouse neuroblastoma (Neuro-2a) cells through caspase-3 activation with down-regulation of XIAP. Toxicol Lett 213: 151-159, 2012.

19. Galluzzi L, Morselli E, Kepp O, et al: Mitochondrial gateways to cancer. Mol Aspects Med 31: 1-20, 2010.

20. $\mathrm{Xu} \mathrm{CX}$, Jin $\mathrm{H}$ and Cho MH: Apoptosis and apoptosis-based therapy in lung cancer. Anticancer Agents Med Chem 9: 952-957, 2009.

21. Huang C, Chen X, Guo B, et al: Induction of apoptosis by Icariside II through extrinsic and intrinsic signaling pathways in human breast cancer MCF7 cells. Biosci Biotechnol Biochem 76: 1322-1328, 2012

22. Zeng C, Ke Z, Song Y, et al: Annexin A3 is associated with a poor prognosis in breast cancer and participates in the modulation of apoptosis in vitro by affecting the $\mathrm{Bcl}-2 / \mathrm{Bax}$ balance. Exp Mol Pathol 95: 23-31, 2013.

23. Wang $\mathrm{C}$ and Youle RJ: The role of mitochondria in apoptosis. Annu Rev Genet 43: 95-118, 2009.

24. Du C, Fang M, Li Y, Li L and Wang X: Smac, a mitochondrial protein that promotes cytochrome c-dependent caspase activation by eliminating IAP inhibition. Cell 102: 33-42, 2000.

25. Verhagen AM, Ekert PG, Pakusch M, et al: Identification of DIABLO, a mammalian protein that promotes apoptosis by binding to and antagonizing IAP proteins. Cell 102: 43-53, 2000.

26. Adrain C, Creagh EM and Martin SJ: Apoptosis-associated release of Smac/DIABLO from mitochondria requires active caspases and is blocked by Bcl-2. EMBO J 20: 6627-6636, 2001.

27. Chipuk JE and Green DR: How do BCL-2 proteins induce mitochondrial outer membrane permeabilization? Trends Cell Biol 18: $157-164,2008$

29. Hengartner MO: The biochemistry of apoptosis. Nature 407 770-776, 2000

29. Fulda S and Vucic D: Targeting IAP proteins for therapeutic intervention in cancer. Nat Rev Drug Discov 11: 109-124, 2012.

30. Salvesen GS and Duckett CS: Apoptosis: IAP proteins: blocking the road to death's door. Nat Rev Mol Cell Biol 3: 401-410, 2002.

31. Ahn KS, Sethi G and Aggarwal BB: Embelin, an inhibitor of $\mathrm{X}$ chromosome-linked inhibitor-of-apoptosis protein, blocks nuclear factor- $\kappa \mathrm{B}(\mathrm{NF}-\kappa \mathrm{B})$ signaling pathway leading to suppression of NF- $\kappa \mathrm{B}$-regulated antiapoptotic and metastatic gene products. Mol Pharmacol 71: 209-219, 2007. 